\title{
Review
}

\section{Physiological Relevance of Renin/Prorenin Binding and Uptake}

\author{
Daniel F. CATANZARO
}

\begin{abstract}
There is compelling physiological evidence of binding and uptake of renin and prorenin in tissues. A number of molecules with the ability to bind renin and prorenin have been identified and have been characterized to varying degrees. It remains unclear, however, just how many renin/prorenin binding proteins and receptors exist and what their physiological functions may be. The possible functions of renin/prorenin binding and uptake are manifold, and include clearance of renin and prorenin from the circulation, local generation of angiotensins, activation of prorenin on the cell surface, trafficking of prorenin between cellular and extracellular compartments as part of a complex processing machinery, and signal transduction both via direct receptor mediated signaling, and via modulation of $\mathrm{O}$-linkage of $\mathrm{N}$-acetyl-glucosamine to cellular proteins. Some of these functions may involve single renin/prorenin binding sites or receptors, while others may require multiple binding sites and receptors. This review describes the physiological studies that have provided evidence of renin/prorenin uptake from the circulation, summarizes our knowledge of renin/prorenin binding proteins and receptors, and postulates new roles for renin/prorenin binding and uptake in tissues. (Hypertens Res 2005; 28: 97-105)
\end{abstract}

Key Words: renin, prorenin, binding site, receptor, processing

\section{Introduction}

Although the role of plasma renin in controlling blood pressure and fluid homeostasis is well understood, the role of renin in tissues remains speculative. Despite some earlier controversy about the synthesis of renin in tissues, it is now generally agreed that renin found in most tissues is taken up from the circulation and is of renal origin $(1,2)$. In addition, prorenin, the inactive precursor of renin, is present in plasma at concentrations often higher than those of active renin. Although various roles for prorenin have been proposed (3, 4), a physiological function for prorenin has never been proven. Recent studies suggest that prorenin may be taken up from the plasma and activated either on cell-surface membranes or intracellularly. These proposed mechanisms raise the question of how renin/prorenin enter tissues, whether by passive or active mechanisms, and, if the process is active, whether these mechanisms are specific or non-specific. Although several renin/prorenin binding and uptake mechanisms have been identified (5-9), their functions are as yet only poorly defined, and it is not clear whether these sites function alone, together, or in combination with other mechanisms.

The importance of renin uptake into tissues is that it provides a mechanism to generate angiotensin II (Ang II) locally in excess of that produced in the plasma. In addition to its vasoconstrictor effects on vascular smooth muscle cells, Ang II initiates a multiplicity of intracellular signals (10) that may cause smooth muscle cell hypertrophy (11-13) or hyperplasia (13-15), which in turn lead to vascular remodeling (15). These effects may also contribute to target organ damage independent of the effects of Ang II on blood pressure $(14,16$, 17).

The goals of this review are to examine the physiological evidence of renin uptake, and to review the binding and

From the Department of Cardiothoracic Surgery, Weill Medical College, Cornell University, New York, USA.

Address for Reprints: Daniel F. Catanzaro, Ph.D., Department of Cardiothoracic Surgery, Weill Medical College, Cornell University, 1300 York Avenue, New York, NY 10021, USA. E-mail: dfcatanz@med.cornell.edu

Received September 30, 2004; Accepted in revised form October 29, 2004. 
uptake mechanisms that have been investigated. Although there is an abundance of physiological data suggesting the function of renin/prorenin uptake in tissues, biochemical studies have lagged in characterizing the underlying mechanisms. In this review I have also attempted to synthesize some of the available data to account for known physiological phenomena, and to suggest possible new roles for renin/prorenin binding and uptake in different tissues.

\section{Physiological Evidence of Renin Uptake}

The concept of a tissue binding site for circulating renin originates from the seminal studies of Tigerstedt and Bergman, who observed that the pressor effect of renal extracts lasted for hours in bilaterally nephrectomized rabbits, compared to minutes in intact animals (18). Later studies confirmed that the prolonged pressor response was due to renin (19-21). Further evidence of renin uptake in vascular tissues was provided by Thurston, Swales and coworkers, who demonstrated angiotensin-dependent blood pressure responses in nephrectomized rats despite rapid clearance of renin from the circulation (22-30). They postulated that blood pressure was maintained by renin taken up by the vasculature (22-24) and showed parallel changes in aortic renin concentration and blood pressure in several rat models: after nephrectomy of Goldblatt two-kidney, one-clip hypertensive rats (24-26), following administration of renin to nephrectomized rats (28, 29), and in other hypertensive models (30). Similar findings were also reported by Bing and Nielsen (31).

Studies of the rate of Ang II production and metabolism in tissues provided further indirect evidence of tissue uptake of renin $(32,33)$. Campbell and coworkers calculated that the venous levels of Ang II were too high to be accounted for by circulating renin and the clearance rate of Ang II (32). Admiraal et al. measured the clearance of radiolabeled Ang I across various tissue beds in humans and found that the venous levels of Ang I were higher than expected, consistent with the presence of enzymatically active renin (33). One explanation for these findings is that tissue binding of renin could result in the local generation of angiotensin, and thereby in the high levels of Ang II such as those that have been measured in the kidney $(34,35)$.

Several transgenic studies also support the concept of renin/ prorenin uptake from the circulation. First, Veniant et al. produced a transgenic rat line that expresses rat prorenin in the liver, resulting in a 500 -fold increase in circulating plasma prorenin levels (36). These rats had normal plasma renin levels and normal blood pressures, but developed severe cardiac hypertrophy. Similarly, Prescott et al. produced doubly transgenic mice expressing active human renin in the liver and human angiotensinogen in the heart (37). Because of the species-specificity of renin and angiotensinogen, Ang I would only be formed by human renin if it entered or were taken up by cardiomyocytes expressing human angiotensinogen. These mice had cardiac fibrosis accompanied by elevated car- diac Ang I and Ang II, but without changes in the circulating levels of these peptides. In another study, this group made doubly transgenic mice that expressed human prorenin in the liver and human angiotensinogen in the heart (38). These mice had elevated circulating levels of human prorenin, but no human angiotensinogen in plasma, and normal circulating plasma angiotensin levels and normal blood pressure. In the heart, there was an increase in Ang I, suggesting uptake and activity of human prorenin. However, there was no change in cardiac Ang II levels, and no physiological effects of Ang II on the heart, suggesting that the Ang I was generated in a compartment devoid of angiotensin converting enzyme (ACE). In other studies, mice overexpressing rat angiotensinogen in myocardium also had ventricular hypertrophy that was corrected by ACE inhibition and Ang II receptor blockade, although the plasma levels of Ang I and Ang II were unaltered (39).

\section{Evidence of a Vascular Site of Renin Uptake}

Renin activity was detected in the arterial wall as early as 1956 by Dengler (40), and later by Gould et al. (41). Indeed, several of the studies described above measured renin activity in the arterial wall $(25,28-30)$ and showed that it correlated with plasma renin levels, and disappeared after nephrectomy. The site of renin uptake was also studied immunocytochemically $(27,42,43)$. Following intravenous injection of mouse submandibular gland renin, renin immunoreactivity was detected predominantly in the media of the descending aorta and the central arteries of the spleen $(27,42)$. Infusion of purified hog renin for several days into hypertensive rabbits resulted in uptake in the aorta, carotid artery and heart, and kidneys, mainly at the site of smooth muscle cells (43). Further indirect evidence of renin uptake into tissues was provided by studies using anti-renin antibodies that blocked its catalytic activity. In those studies, Ang II antagonists had a greater effect than anti-renin antibodies in reducing hypertension resulting from renin infusion (23), or Goldblatt two-kidney, one-clip hypertensive rats (44), suggesting that the location of the renin may not be accessible to the larger antibody molecule.

\section{Biochemical and Molecular Evidence of Renin/Prorenin Binding}

Renin angiotensin system (RAS) components may enter tissues in several ways. Measurements of tissue levels of such components and their comparison to plasma levels suggest that both can diffuse from the plasma into the interstitial spaces where angiotensin peptides are generated $(45,46)$. Biochemical studies of isolated perfused beating hearts have further shown that angiotensin peptides can be formed in the interstitial spaces $(47,48)$. These studies imply that renin and angiotensinogen may pass through the endothelial cell layer into the subendothelial spaces. This could occur by pressure- 
mediated ultrafiltration through endothelial pores, as has been described in the glomerulus (49-51), or via other channels across endothelial membranes $(52,53)$. However, the exact paths whereby renin and angiotensinogen enter tissues have not been determined.

In addition to transendothelial passage, several of the studies described above have provided evidence of renin uptake $(45,54)$. We currently have knowledge of several renin- and prorenin-binding sites, which differ in their localization, specificity, and degree of characterization. Our present knowledge of these sites is discussed in the following section.

\section{Renin Binding Protein (RnBP)}

$\mathrm{RnBP}$ is a soluble renin binding protein $(42,000 \mathrm{Da})$ that was originally identified in dog kidney (5). Yamamoto and coworkers observed that renin purified from the granule fraction of dog kidneys had a molecular weight of 43,000 Da, whereas renin purified from crude renal extract in the presence of thiol inhibitors had a molecular weight (MW) of $60,000 \mathrm{Da}$ (55-57). Mixing of low MW renin from the granule fraction with a kidney cytosol fraction in the presence of sodium tetrathionate resulted in the formation of $60,000 \mathrm{Da}$ renin (5).

RnBP was found in cortical tubular cells, but not in the glomeruli $(58,59)$, and subcellular fractionation of rat kidney extracts revealed that most of the RnBP is contained in the cytosol (60). Recent studies using in situ hybridization to localize RnBP mRNA in rat kidney have yielded conflicting findings. One reported RnBP mRNA in the glomerulus (most likely in mesangial cells) (61), while another found RnBP mRNA in renal tubules (62).

Functionally, RnBP inhibits renin activity, which suggested that it might be involved in the regulation of RAS activity (63). However, because RnBP is a cytosolic protein and is therefore not secreted from the cell, it seems unlikely that it could be involved in the regulation of circulating RAS activity. Under normal conditions, renin probably does not come in contact with RnBP, at least in the plasma, and binding of renin to $\mathrm{RnBP}$ in cellular extracts may thus be an artifact of the extraction process. Leckie and coworkers found no changes in the renal levels of RnBP in the kidneys of rats with two-kidney one-clip hypertension, despite upregulation of renin expression in the clipped kidney (62). RnBP knockout mice, which completely lack the protein, have normal blood pressure, normal RAS activity, and respond normally to physiological stimuli that perturb the RAS. Taken together, these observations suggest that RnBP is not involved in the regulation of RAS activity or blood pressure.

\section{RnBP Has $\mathrm{N}$-Acyl-glucosamine, 2-epimerase Activity}

RnBP has also been recognized as the enzyme $N$-acyl-glucosamine, 2-epimerase (NAGE), which catalyzes the intra- conversion of $\mathrm{N}$-acetyl-glucosamine (GlcNAc) and $\mathrm{N}$ acetylmannosamine (64). Although RnBP/NAGE knockout mice have normal blood pressure, and normal excretion of $\mathrm{N}$ acetyl-neuraminic acid (NANA—one of the principal metabolites of GlcNAc), they do excrete large amounts of an unknown oligosaccharide into the urine (61). In contrast, constitutive activation of the unidirectional UDP-dependent GlcNAc-2-epimerase causes developmental delay, and excessive NANA secretion (sialuria) (65). Recently, Bohlmeyer et al. reported an increase in RnBP in failing human hearts (66). Specifically, they observed redistribution in expression from microvascular endothelial cells to cardiac myocytes, and RnBP expression was highly correlated to pulmonary capillary wedge pressure among patients with end-stage idiopathic cardiomyopathy. Bohlmeyer et al (66). point out that RnBP/ NAGE could be involved in modulating O-linkage of GlcNAc to cytoplasmic proteins by controlling the availability of GlcNAc (67). O-linkage of GlcNAc competes with phosphorylation of serine and threonine residues, is reversible, occurs with sufficient rapidity to serve a signaling/regulatory function, and has been shown to affect the activity and stability of several transcription factors and receptors (68). In the heart, O-linkage of GlcNAc might regulate alpha B-crystallin, which has been shown to play a cardioprotective role (66).

It is noteworthy that as RnBP/NAGE inhibits renin activity, so too renin inhibits NAGE activity (69). Therefore, it is possible that renin taken up into RnBP/NAGE-expressing cells might regulate NAGE activity. Although an earlier study found no evidence of changes in RnBP expression associated with changes in renal and circulating renin levels, the effects of RAS changes on the RnBP epimerase activities were not examined (62). More recently, a nonsecretable form of renin was identified $(70,71)$. Peters and Clausmeyer demonstrated a four-fold increase in the mRNA in response to myocardial ischemia (72). This intracellular form of renin might also be involved in the regulation of NAGE activity.

\section{Membrane-Associated Binding Sites}

The cellular localization of RnBP suggests that it is unlikely to play a primary role in renin binding/uptake from plasma. However, earlier studies showed that although about $70 \%$ of kidney granule renin is released rapidly following isosmotic shock, 20\% was released more slowly, and another $8 \%$ was retained in the insoluble fraction $(73,74)$, suggesting that other membrane-associated renin binding sites might also be present.

Campbell and Valentijn (6) described a membrane binding site for ${ }^{125}$ I-labeled renin that was most abundant in the mesenteric artery, and present at lower levels in the aorta, lung, and renal medulla, but not in the kidney cortex. However, they were unable to demonstrate saturable binding. Binding to mesenteric artery membranes was competed by the renin inhibitor SQ 30697, suggesting the involvement of 
the active site in binding that would result in the inhibition of renin activity. Such a site would therefore be unlikely to contribute to the tissue generation of Ang I.

Using recombinant, metabolically labeled ${ }^{35} \mathrm{~S}$ prorenin as a probe, Sealey and coworkers found evidence of a high affinity binding site in microsomal membranes of several tissues that bind both renin and prorenin (ProBP) (7). Relative binding was highest in the kidney, testes, and lung, lower in the brain, renal medulla, adrenal, heart, and aorta, and very low in skeletal muscle. The affinities for the renin and prorenin to binding sites in the preparations of renal cortex were in the $0.1-$ $1.0 \mathrm{nmol} / 1 \mathrm{range}$. The binding capacity of the renin/prorenin binding was around $200 \mathrm{fmol} / \mathrm{mg}$ membrane protein, which could bind sufficient renin to generate the excess Ang I in the range reported across the renal vasculature (32). Renin/prorenin binding was reversible, saturable, and $\mathrm{pH}-$ and temperature-dependent. The bound rat renin/prorenin was displaced by human renin/prorenin, but not by any of a variety of other potential ligands tested. Moreover, the binding did not appear to affect renin activity, nor did binding of prorenin result in its activation.

\section{Mannose-6-phosphate (M6P)/Insulin-Like Growth Factor Receptor}

More recently, Admiraal et al. reported uptake of renin/prorenin on endothelial cell membranes via the M6P receptor (8). This receptor binds proteins containing M6P, and also binds insulin-like growth factor II (IGFII) at an allosteric site. The M6P/IGFII receptor $(\mathrm{R})$ has been shown to participate in the activation of latent transforming-growth factor $\beta$ (TGF $\beta$ ), possibly by inducing a conformational change that allows it to be cleaved by plasmin or other proteinases, or by creating a local environment with favorable kinetics (e.g., high local concentrations of substrate and enzyme) (75). Binding to the M6P/IGFIIR leads to the activation of prorenin, and to the clearance of renin and prorenin $(8,76,77)$. Local uptake of renin/prorenin may thus contribute to Ang II formation in the interstitial spaces of tissues, including those of the heart (77). Uptake of active renin into cells, or activation and uptake of prorenin, could provide a mechanism to generate Ang II intracellularly. Such a mechanism has been proposed to explain high intracellular levels of Ang II found in various tissues and has led to speculation concerning possible intracellular actions of Ang II $(78,79)$. However, evidence for intracellular generation of Ang II could only be obtained when cells were transfected with a construct encoding a non-secretable form of angiotensinogen (78). Schuijt and Danser argued against the intracellular formation of Ang II, because of the absence of intracellular angiotensinogen and ACE (80), and the finding that incubation of cardiomyocytes in the presence of both prorenin and angiotensinogen failed to produce intracellular angiotensins (81). They concluded that the high intracellular concentrations of Ang II in tissues are more likely due to uptake and clearance of extracellular Ang II via the Ang II type 1 receptor (AT1R) (80). Nonetheless, the M6P/IGFIIR may mediate extracellular Ang II generation in the heart (79).

Another line of evidence suggests that uptake may occur independently of the M6P/IGFIIR. The TGR(mREN2)27 transgenic rat expresses the unglycosylated mouse ren- $2^{\mathrm{d}}$ gene under the control of its own promoter. This transgenic rat line has high levels of circulating unglycosylated prorenin, and develops cardiac hypertrophy (82-84). Peters and coworkers showed that adult cardiomyocytes can internalize unglycosylated prorenin and can generate angiotensins (85). In addition, hepatic expression of the ren- $2^{\mathrm{d}}$ under the control of an inducible promoter led to a marked rise in circulating and cardiac intracellular levels of unglycosylated renin and prorenin associated with hypertension, microinfarctions, necrosis, and inflammatory responses in cardiac tissue (86). However, the findings of such studies may depend on the species and the system used to express the RAS components and hence their cellular localization.

\section{Expression Cloning of a Renin/Prorenin Receptor}

Nguyen et al. used expression cloning to isolate a renin/prorenin receptor, although the method used to screen the cDNA library from which this clone was identified was not specified (9). They identified a human recombinant cDNA encoding a 350 -amino acid protein with a single transmembrane domain that was expressed in the heart, brain and placenta, and at lower levels in the kidney and liver. The receptor was found in glomerular mesangial cells, as well as the subendothelium of renal and coronary arteries. Stably transfected cell lines expressing the receptor specifically bound renin and prorenin. Binding increased the catalytic activity of renin and appeared to activate prorenin, and also transduced an intracellular signal via extracellular signal-regulated kinase (ERK)1 and ERK2 mitogen-activated protein (MAP) kinases.

Further characterization of this site should include the preparation of knockout mice in which the gene encoding the receptor is inactivated. However, caution should be exercised in interpreting the findings of RAS studies in mice. Although mice have plasma renin activities and Ang I and Ang II levels similar to those of other species, mice achieve these levels very differently from most, if not all other species in which the RAS has been characterized. Mice have approximately 100 -fold higher plasma renin, and correspondingly lower circulating angiotensinogen than other species $(87,88)$. The excess renin in mouse plasma may require adaptation of any secondary system involving binding proteins or receptors. Other approaches to investigating the function(s) of this renin/prorenin receptor might involve overexpression in different tissues in mice and rats.

\section{Implications of Renin/Prorenin Binding and Uptake}

With the exception of the M6P/IGFIIR analyzed by Danser's 
group, none of the membrane binding sites have been characterized beyond the initial reports. Only one novel specific receptor has been cloned (9), and the biological significance of this site remains to be determined. To date, no one has provided biochemical verification that any one of the renin/prorenin binding sites/receptors has a physiological function in the whole animal. However, there are a number of functions these sites could serve, which are discussed below.

\section{Local Generation of Angiotensins}

Most of the membrane-associated renin/prorenin binding sites that have been identified occur in relatively low abundance and are therefore difficult to isolate and study. Nonetheless, they may be present in sufficient quantities to explain the physiological differences in Ang I concentrations observed across vascular beds. In tissues that produce high levels of prorenin, renin binding may be displaced from receptors by prorenin. Binding to $\mathrm{M} 6 \mathrm{P} / \mathrm{IGFII}$ or renin/prorenin receptors might activate prorenin. In the case of the $\mathrm{M} 6 \mathrm{P} /$ IGFIIR, prorenin is activated only after intracellular sequestration, and thus it is unlikely to contribute to the generation of extracellular Ang II. However, the renin/prorenin receptor appears both to increase the activity of bound renin, and to activate bound prorenin. This could lead to the generation of extracellular Ang II with local vasoconstrictor and vasculotoxic effects. If these functions of this receptor could be validated, the renin/prorenin receptor would be a potential target for anti-RAS drugs $(89,90)$. Together, binding of renin/prorenin to one or a number of membrane sites could account for the excess angiotensins reported across vascular beds in physiological studies $(32,33)$.

\section{Buffering the Effects of Circulating Renin}

Thurston and Swales originally proposed that renin in tissues maintains normal blood pressure (26). However, this need not exclude a role for the circulating RAS, which may respond to short-term changes induced by changes in posture, or hemorrhage. Organ systems may depend on renin uptake to maintain vascular tone, or other direct effects of Ang II or renin on tissues.

The blood flow requirements of different organs are determined primarily by their vascularity. However, Ang II receptor distribution and density could affect the sensitivity to Ang II, and the presence of a renin uptake mechanism, with the capacity to generate Ang II locally, could buffer fluctuations in circulating renin levels by integrating the plasma renin activity over time. The degradative functions proposed for the M6P/IGFIIR are also important to permit adaptation to circulating levels of RAS components. It is also conceivable that one receptor functions as the capture site where Ang I generation occurs, and another receptor acts to clear the bound renin. Such configurations would enable different vascular beds to adjust their sensitivity to fluctuations in renal renin release, and thus provide a mechanism to modulate the RAS effects in different organs ultimately regulated by a master control exerted at the level of renin released from the kidney.

\section{Role in Prorenin Processing}

In addition to its physiological role in mediating RAS in tissues, the M6P/IGFIIR provides a model for prohormone processing. Binding to this receptor has been shown to be required for cellular activation of latent TGF $\beta$ via proteolysis or other activating mechanisms (75). Similarly, prorenin could be secreted and then taken up by cells to be activated intracellularly as described by Danser and coworkers (79). Although the lack of intracellular angiotensinogen led them to conclude that this is most likely a degradative pathway, specialization of the lysosomal granules of juxtaglomerular cells might allow these cells to secrete active renin that is processed from prorenin secreted by those cells, and then taken up again. This is analogous to the processing of thyroglobulin which must be secreted for iodination to occur, but is then taken up again for conversion to $\mathrm{T}_{3}$ and $\mathrm{T}_{4}(91)$. It is also consistent with the correlation between circulating concentrations of renin and prorenin $(87,88)$. Although, at this time, there is no evidence of the secretion of activated prorenin from endothelial cells where this possibility has been tested (92), the proteinase responsible for processing prorenin in smooth muscle cell-derived juxtaglomerular cells has yet to be identified, and perhaps models more complex than mere matching of an enzyme to a substrate will need to be evaluated $(93,94)$.

\section{Modulation of NAGE Activity —A Role in Diabetes}

Renin uptake may also modulate RnBP/NAGE activity. In the glomerulus, the renin/prorenin receptor and RnBP/NAGE both appear to be expressed in mesangial cells. Thus, if the renin/prorenin receptor were also capable of translocating renin to the cytoplasm, it could be a mechanism to modulate NAGE activity. It is not known whether M6P/IGFIIR is present on mesangial cells, although it could also play a role at this site. In the heart, M6P/IGFIIR translocates renin into the myocytes where RnBP/NAGE is expressed under conditions of heart failure. Under these conditions renin uptake could reduce NAGE activity, resulting in either an increase or a decrease in GlcNAc, which could then affect intracellular signaling by altering the balance of O-linkage of GlcNAc/ phosphorylation. It is especially intriguing that O-linkage of GlcNAc is affected by glucose concentration (95) and is involved in insulin signaling (96). RAS blockade is known to improve target organ damage in diabetic patients $(97,98)$, and has been shown to improve insulin resistance in animal models (99). Although much of the benefit results from reduced AT1R stimulation, the addition of $\beta$-blockers to ACE inhibitor and diuretic therapy reduced the incidence of congestive 
heart failure (100), and $\beta$-blockers alone appear to be beneficial in diabetic patients with congestive heart failure (101). These observations raise the possibility that plasma renin levels, which are reduced by $\beta$-blockers (102), may play a direct role, mediated by uptake via one or more of the receptor/binding sites and signal transduction via RnBP/NAGE.

\section{Summary and Conclusions}

There is considerable physiological evidence in support of renin uptake from the circulation and local generation of Ang II in tissues. A number of renin/prorenin binding sites have been identified. However, it is not known whether any of these sites mediate renin uptake in vivo. Each of the identified sites appears to have different biochemical characteristics, and several have not been further studied beyond the initial report. Thus, it remains possible that some of the less-wellcharacterized sites are the same. Among those sites, ProBP and the renin/prorenin receptor have the potential to bind renin and generate angiotensins locally. The renin/prorenin receptor might also activate prorenin, and transduce intracellular signals. However, further characterization is required. M6P/IGFIIR might also be involved in the local binding of renin/prorenin, and may further serve a clearance function. M6P/IGFIIR may also be involved in cycling prorenin between the Golgi, extracellular space, and lysosomal compartments of juxtaglomerular cells as part of a complex processing network similar to that involved in the conversion of thyroglobulin to thyroid hormones. However, there may be other receptors/binding sites involved, as suggested by transgenic studies of unglycosylated prorenin. Because RnBP/ NAGE is localized intracellularly, it is unlikely to play a role in the local generation of Ang II. However, it may be involved in signal transduction because of its potential role in modulating GlcNAc levels, and hence in modulating O-linkage of GlcNAc to serine and threonine residues. Since M6P/IGFIIR and RnBP/NAGE may both be expressed in cardiomyocytes, together they may function to modulate cellular activities in failing heart cells in response to circulating renin and/or prorenin levels. Similarly, in the glomerulus, RnBP/NAGE may function together with the renin/prorenin receptor to modulate intracellular activity in response to renin and/or prorenin. Thus, more than one renin/prorenin binding protein/receptor may be required in mediating a physiological response. Further characterizations of these binding proteins and receptors and the biochemical and physiological functions they subserve are warranted.

\section{Acknowledgements}

I thank Drs. A.H. Jan Danser and Timothy L. Reudelhuber for their critical reading of the manuscript and their valuable suggestions.

\section{References}

1. von Lutterotti N, Catanzaro DF, Sealey JE, Laragh JH: Renin is not synthesized by cardiac and extrarenal vascular tissues: a review of experimental evidence. Circulation 1994; 89: 458-470.

2. Saris JJ, Derkx FH, De Bruin RJ, et al: High-affinity prorenin binding to cardiac man-6-P/IGF-II receptors precedes proteolytic activation to renin. Am J Physiol Heart Circ Physiol 2001; 280: H1706-H1715.

3. Sealey JE, von Lutterotti N, Rubattu S, et al: The greater renin system. Its prorenin-directed vasodilator limb. Relevance to diabetes mellitus, pregnancy, and hypertension. Am J Hypertens 1991; 4: 972-977.

4. Hsueh WA, Baxter JD: Human prorenin. Hypertension 1991; 17: 469-477.

5. Kawamura M, Ikemoto F, Funakawa S, Yamamoto K: Characteristics of a renin-binding substance for the conversion of renin into a higher-molecular-weight form in the dog. Clin Sci 1979; 57: 345-350.

6. Campbell DJ, Valentijn AJ: Identification of vascular reninbinding proteins by chemical cross-linking: inhibition of binding of renin by renin inhibitors. J Hypertens 1994; 12: 879-890.

7. Sealey JE, Catanzaro DF, Lavin TN, et al: Specific prorenin/ renin binding (ProBP). Identification and characterization of a novel membrane site. Am J Hypertens 1996; 9: 491-502.

8. Admiraal PJ, van Kesteren CA, Danser AHJ, Derkx FH, Sluiter W, Schalekamp MADH: Uptake and proteolytic activation of prorenin by cultured human endothelial cells. $J$ Hypertens 1999; 17: 621-629.

9. Nguyen G, Delarue F, Burckle C, Bouzhir L, Giller T, Sraer JD: Pivotal role of the renin/prorenin receptor in angiotensin II production and cellular responses to renin. J Clin Invest 2002; 109: 1417-1427.

10. Berk BC: Angiotensin II signal transduction in vascular smooth muscle: pathways activated by specific tyrosine kinases. J Am Soc Nephrol 1999; 10: S62-S68.

11. Naftilan AJ, Pratt RE, Dzau VJ: Induction of platelet-derived growth factor A-chain and c-myc gene expressions by angiotensin II in cultured rat vascular smooth muscle cells. J Clin Invest 1989; 83: 1419-1424.

12. Geisterfer AA, Peach MJ, Owens GK: Angiotensin II induces hypertrophy, not hyperplasia, of cultured rat aortic smooth muscle cells. Circ Res 1988; 62: 749-756.

13. Sung CP, Arleth AJ, Storer BL, Ohlstein EH: Angiotensin type 1 receptors mediate smooth muscle proliferation and endothelin biosynthesis in rat vascular smooth muscle. $J$ Pharmacol Exp Ther 1994; 271: 429-437.

14. Su EJ, Lombardi DM, Siegal J, Schwartz SM: Angiotensin II induces vascular smooth muscle cell replication independent of blood pressure. Hypertension 1998; 31: 1331-1337.

15. Daemen MJ, Lombardi DM, Bosman FT, Schwartz SM: Angiotensin II induces smooth muscle cell proliferation in the normal and injured rat arterial wall. Circ Res 1991; 68: 450-456.

16. Harrison DG: Endothelial function and oxidant stress. Clin Cardiol 1997; 20: 11-17.

17. Taniyama Y, Griendling KK: Reactive oxygen species in the 
vasculature: molecular and cellular mechanisms. Hypertension 2003; 42: 1075-1081.

18. Tigerstedt R, Bergman PG: Niere und Kreislauf. Skand Arch Physiol 1898; 8: 223-271.

19. Bing J: Mechanism of the increased sensitivity to renin in nephrectomized animals. Acta Pathol Scand 1963; 60: 311.

20. Blaquier P, Hoobler SW, Schroeder J, Gomez A, Kreulen T: Effect of bilateral nephrectomy on pressor response to renin. Am J Physiol 1962; 203: 339-342.

21. Carretero O, Gross F: Evidence for humoral factors participating in the renin-substrate reaction. Circ Res 1966; 20 -21 (Suppl II): 115-127.

22. Swales JD, Thurston H: Generation of angiotensin II at peripheral vascular level: studies using angiotensin II antisera. Clin Sci Mol Med 1973; 45: 691-700.

23. Thurston H, Swales JD: Action of angiotensin antagonists and antiserum upon the pressor response to renin: further evidence for the local generation of angiotensin II. Clin Sci Mol Med 1974; 46: 273-276.

24. Thurston H, Swales JD: Blood pressure response of nephrectomized hypertensive rats to converting enzyme inhibition: evidence for persistent vascular renin activity. Clin Sci Mol Med 1977; 52: 299-304.

25. Thurston H, Hurst BC, Bing RF, Swales JD: Role of persistent vascular renin after bilateral nephrectomy in Goldblatttwo kidney hypertension. Clin Sci Mol Med Suppl 1978; 4: $23 \mathrm{~s}-26 \mathrm{~s}$.

26. Thurston H, Swales JD, Bing RF, Hurst BC, Marks ES: Vascular renin-like activity and blood pressure maintenance in the rat. Studies of the effect of changes in sodium balance, hypertension and nephrectomy. Hypertension 1979; 1: 643649.

27. Swales JD: Arterial wall or plasma renin in hypertension. Clin Sci 1979; 56: 293-298.

28. Loudon M, Bing RF, Swales JD, Thurston H: Vascular renin as a determinant of the circulatory response to renin. Clin Exp Hypertens 1982; 4: 2049-2061.

29. Loudon M, Bing RF, Thurston H, Swales JD: Arterial wall uptake of renal renin and blood pressure control. Hypertension 1983; 5: 629-634.

30. Swales JD, Loudon M, Bing RF, Thurston H: Renin in the arterial wall. Clin Exp Hypertens 1983; 5: 1127-1136.

31. Bing J, Nielsen K: Role of the renin-system in normo- and hypertension. Effect of angiotensin-inhibitor (1-sar-8-alaangiotensin II) on the blood pressure of conscious or anaesthetized normal, nephrectomized and renal hypertensive rats. Acta Pathol Microbiol Scand 1973; 81: 254-262.

32. Campbell DJ, Lawrence AC, Towrie A, Kladis A, Valentijn AJ: Differential regulation of angiotensin peptide levels in plasma and kidney of the rat. Hypertension 1991; 18: 763773.

33. Admiraal PJJ, Danser AHJ, de Jong M, Pieterman H, Derkx FHM, Schalekamp MADH: Regional angiotensin II production in essential hypertension and renal artery stenosis. Hypertension 1993; 21: 173-184.

34. Seikaly MG, Arant BSJ, Seney FD Jr: Endogenous angiotensin concentrations in specific intrarenal fluid compartments of the rat. J Clin Invest 1990; 86: 1352-1357.

35. Braam B, Mitchell KD, Fox J, Navar LG: Proximal tubular secretion of of angiotensin II in rats. Am J Physiol 1993; 264:
F891-F898.

36. Veniant M, Menard J, Bruneval P, Morley S, Gonzales MF, Mullins J: Vascular damage without hypertension in transgenic rats expressing prorenin exclusively in the liver. J Clin Invest 1996; 98: 1966-1970.

37. Prescott G, Silversides DW, Chiu SM, Reudelhuber TL: Contribution of circulating renin to local synthesis of angiotensin peptides in the heart. Physiol Genomics 2000; 4: 6773.

38. Prescott G, Silversides DW, Reudelhuber TL: Tissue activity of circulating prorenin. Am J Hypertens 2002; 15: 280-285.

39. Mazzolai L, Pedrazzini T, Nicoud F, Gabbiani G, Brunner HR, Nussberger J: Increased cardiac angiotensin II levels induce right and left ventricular hypertrophy in normotensive mice. Hypertension 2000; 35: 985-991.

40. Dengler H: Concerning a renin-like active substance in extracts from arteries. Naunyn Schmiedebergs Arch Pharmacol 1956; 227: 481-487.

41. Gould AB, Skeggs LT, Kahn JR: The presence of renin activity in blood vessel walls. $J$ Exp Med 1964; 119: 389399.

42. Swales JD, Abramovici A, Beck F, Bing RF, Loudon M, Thurston H: Arterial wall renin. J Hypertens Suppl 1983; 1: $17-22$.

43. Skeggs LT, Dorer FE, Lentz KE, Kahn JR, Emancipator S: A new mechanism in one-kidney, one-clip hypertension. Hypertension 1985; 7: 72-80.

44. Thurston H, Swales JD: Comparison of angiotensin II antagonist and antiserum infusion with nephrectomy in the rat with two-kidney goldblatt hypertension. Circ Res 1974; 35: 325-329.

45. Danser AHJ, van Kats JP, Admiraal PJ, et al: Cardiac renin and angiotensins. Uptake from plasma versus in situ synthesis. Hypertension 1994; 24: 37-48.

46. Heller LJ, Opsahl JA, Wernsing SE, Saxena R, Katz SA: Myocardial and plasma renin-angiotensinogen dynamics during pressure-induced cardiac hypertrophy. Am J Physiol 1998; 274: R849-R856.

47. Lindpaintner K, Jin MW, Niedermaier N, Wilhelm MJ, Ganten D: Cardiac angiotensinogen and its local activation in the isolated perfused beating heart. Circ Res 1990; 67: 564-573.

48. de Lannoy LM, Danser AHJ, Bouhuizen AM, Saxena PR, Schalekamp MADH: Localization and production of angiotensin II in the isolated perfused rat heart. Hypertension 1998; 31: 1111-1117.

49. Rosivall L, Razga Z, Mirzahosseini S, Tornoci L: Endothelial permeability of the afferent arteriole and its changes as the result of alteration in the activity of the renin-angiotensin system. J Am Soc Nephrol 1999; 10 (Suppl 11): S172-S177.

50. Rosivall L, Taugner R: The morphological basis of fluid balance in the interstitium of the juxtaglomerular apparatus. Cell Tissue Res 1986; 243: 525-533.

51. Tiedemann K, Egerer G: Vascularization and glomerular ultrastructure in the pig mesonephros. Cell Tissue Res 1984; 238: $165-175$.

52. Bendayan M: Morphological and cytochemical aspects of capillary permeability. Microsc Res Tech 2002; 57: 327349.

53. Edens H, Parkos C: Modulation of epithelial and endothelial 
paracellular permeability by leukocytes. Adv Drug Deliv Rev 2000; 41: 315-328.

54. de Lannoy LM, Danser AHJ, van Kats JP, Schoemaker RG, Saxena PR, Schalekamp MADH: Renin-angiotensin system components in the interstitial fluid of the isolated perfused rat heart. Local production of angiotensin I. Hypertension 1997; 29: 1240-1251.

55. Takaori K, Funakawa S, Ikemoto F, Yamamoto K: Low molecular weight renin as a storage form in renin granules of the dog. Biochem Biophys Res Commun 1979; 91: 214-221.

56. Funakawa S, Ikemoto F, Kawamura M, Yamamoto K: Relationship between molecular weight conversion and renin activity in dog renal renin. Jpn Circ J 1979; 43: 183-189.

57. Funakawa S, Funae Y, Yamamoto K: Conversion between renin and high-molecular-weight renin in the dog. Biochem $J$ 1979; 176: 977-981.

58. Ikemoto F, Takaori K, Iwao H, Yamamoto K: Intrarenal localization of renin binding substance in rats. Life Sci 1982; 31: 1011-1016.

59. Takaori K, Iwao H, Ikemoto F, Yamamoto K: Specific distribution of renin binding protein in rat and dog kidney. Clin Exp Hypertens 1982; 4: 2097-2105.

60. Murakami K, Hirose S, Chino S, Ueno N, Miyazaki H: Properties of renin-binding protein. Clin Exp Hypertens 1982; 4: 2073-2081.

61. Schmitz C, Gotthardt M, Hinderlich S, et al: Normal blood pressure and plasma renin activity in mice lacking the reninbinding protein, a cellular renin inhibitor. J Biol Chem 2000; 275: $15357-15362$.

62. Leckie BJ, Lacy PS, Lidder S: The expression of renin-binding protein and renin in the kidneys of rats with two-kidney one-clip hypertension. J Hypertens 2000; 18: 935-943.

63. Inoue $\mathrm{H}$, Takahashi $\mathrm{S}$, Miyake $\mathrm{Y}$ : Modulation of active renin secretion by renin-binding protein $(\mathrm{RnBP})$ in mouse pituitary AtT-20 cells transfected with human renin and RnBP cDNAs. J Biochem (Tokyo) 1992; 111: 407-412.

64. Maru I, Ohta Y, Murata K, Tsukada Y: Molecular cloning and identification of $\mathrm{N}$-acyl-D-glucosamine 2-epimerase from porcine kidney as a renin-binding protein. $\mathrm{J}$ Biol Chem 1996; 271: 16294-16299.

65. Weiss P, Tietze F, Gahl WA, Seppala R, Ashwell G: Identification of the metabolic defect in sialuria. $\mathrm{J}$ Biol Chem 1989; 264: 17635-17636.

66. Bohlmeyer T, Ferdensi A, Bristow MR, Takahashi S, Zisman LS: Selective activation of $N$-acyl-D-glucosamine 2epimerase expression in failing human heart ventricular myocytes. J Card Fail 2003; 9: 59-68.

67. Boehmelt G, Wakeham A, Elia A, et al: Decreased UDPGlcNAc levels abrogate proliferation control in EMeg32deficient cells. EMBO J 2000; 19: 5092-5104.

68. Wells L, Vosseller K, Hart GW: Glycosylation of nucleocytoplasmic proteins: signal transduction and $\mathrm{O}$-GlcNAc. Science 2001; 291: 2376-2378.

69. Takahashi S, Kumagai M, Shindo S, Saito K, Kawamura Y: Renin inhibits $\mathrm{N}$-acetyl-D-glucosamine 2-epimerase (reninbinding protein). J Biochem (Tokyo) 2000; 128: 951-956.

70. Clausmeyer S, Reinecke A, Farrenkopf R, Unger T, Peters J: Tissue-specific expression of a rat renin transcript lacking the coding sequence for the prefragment and its stimulation by myocardial infarction. Endocrinology 2000; 141: 2963-
2970.

71. Clausmeyer S, Sturzebecher R, Peters J: An alternative transcript of the rat renin gene can result in a truncated prorenin that is transported into adrenal mitochondria. Circ Res 1999; 84: $337-344$.

72. Peters J, Clausmeyer S: Intracellular sorting of renin: cell type specific differences and their consequences. $\mathrm{J} \mathrm{Mol} \mathrm{Cell}$ Cardiol 2002; 34: 1561-1568.

73. Funakawa S, Funae Y, Yamamoto K: Conversion between renin and high-molecular-weight renin in the dog. Biochem $J$ 1978; 176: 977-981.

74. Funakawa S, Higashio T, Yamamoto K: Renin release from renin granules in the dog. Clin Sci Mol Med 1978; 55: 1114.

75. Dennis PA, Rifkin DB: Cellular activation of latent transforming growth factor beta requires binding to the cationindependent mannose 6-phosphate/insulin-like growth factor type II receptor. Proc Natl Acad Sci USA 1991; 88: 580584.

76. van den Eijnden MM, Saris JJ, de Bruin RJ, et al: Prorenin accumulation and activation in human endothelial cells: importance of mannose 6-phosphate receptors. Arterioscler Thromb Vasc Biol 2001; 21: 911-916.

77. Saris JJ, Derkx FH, Lamers JMJ, Saxena PR, Schalekamp MA, Danser AHJ: Cardiomyocytes bind and activate native human prorenin: role of soluble mannose 6-phosphate receptors. Hypertension 2001; 37: 710-715.

78. Cook JL, Zhang Z, Re RN: In vitro evidence for an intracellular site of angiotensin action. Circ Res 2001; 89: 11381146.

79. Danser AHJ: Local renin-angiotensin systems: the unanswered questions. Int J Biochem Cell Biol 2003; 35: 759768.

80. Schuijt MP, Danser AHJ: Cardiac angiotensin ii: an intracrine hormone? Am J Hypertens 2002; 15: 1109-1116.

81. Saris JJ, van den Eijnden MM, Lamers JMJ, Saxena PR, Schalekamp MADH, Danser AHJ: Prorenin-induced myocyte proliferation: no role for intracellular angiotensin II. Hypertension 2002; 39: 573-577.

82. Mullins JJ, Peters J, Ganten D: Fulminant hypertension in transgenic rats harbouring the mouse Ren-2 gene. Nature 1990; 344: 541-544.

83. Bachmann S, Peters J, Engler E, Ganten D, Mullins J: Transgenic rats carrying the mouse renin gene-morphological characterization of a low-renin hypertension model. Kidney Int 1992; 41: 24-36.

84. Bohm M, Lee MA, Kreutz R, et al: Angiotensin II receptor blockade in TGR(mREN2)27: effects of renin-angiotensinsystem gene expression and cardiovascular functions. $J$ Hypertens 1995; 13: 891-899.

85. Peters J, Farrenkopf R, Clausmeyer S, et al: Functional significance of prorenin internalization in the rat heart. Circ Res 2002; 90: 1135-1141.

86. Kantachuvesiri S, Fleming S, Peters J, et al: Controlled hypertension, a transgenic toggle switch reveals differential mechanisms underlying vascular disease. J Biol Chem 2001; 276: $36727-36733$.

87. Yan Y, Chen R, Pitarresi T, et al: Kidney is the only source of human plasma renin in $45 \mathrm{~kb}$ hREN transgenic mice. Circ Res 1998; 83: 1279-1288. 
88. Yan Y, Hu L, Chen R, Laragh JH, Sealey JE, Catanzaro DF: Appropriate regulation of human renin gene expression and secretion in $45 \mathrm{~kb}$ human renin transgenic mice. Hypertension 1998; 32: 205-214.

89. Nguyen G, Burckle C, Sraer JD: The renin receptor: the facts, the promise and the hope. Curr Opin Nephrol Hypertens 2003 ; 12: 51-55.

90. Nguyen G, Burckle CA, Sraer JD: Renin/prorenin-receptor biochemistry and functional significance. Curr Hypertens Rep 2004; 6: 129-132.

91. Herzog V, Neumuller W, Holzmann B: Thyroglobulin, the major and obligatory exportable protein of thyroid follicle cells, carries the lysosomal recognition marker mannose-6phosphate. EMBO J 1987; 6: 555-560.

92. van den Eijnden MM, de Bruin RJ, de Wit E, et al: Transendothelial transport of renin-angiotensin system components. J Hypertens 2002; 20: 2029-2037.

93. Ichihara A, Hayashi M, Hirota N, et al: Angiotensin II type 2 receptor inhibits prorenin processing in juxtaglomerular cells. Hypertens Res 2003; 26: 915-921.

94. Hirota N, Ichihara A, Koura Y, Tada Y, Hayashi M, Saruta $\mathrm{T}$ : Transmural pressure control of prorenin processing and secretion in diabetic rat juxtaglomerular cells. Hypertens Res 2003; 26: 493-501.

95. McClain DA, Crook ED: Hexosamines and insulin resistance. Diabetes 1996; 45: 1003-1009.

96. Hart GW: Dynamic O-linked glycosylation of nuclear and cytoskeletal proteins. Annu Rev Biochem 1997; 66: 315-335.

97. Gilbert RE, Krum H, Wilkinson-Berka J, Kelly DJ: The renin-angiotensin system and the long-term complications of diabetes: pathophysiological and therapeutic considerations. Diabet Med 2003; 20: 607-621.

98. Hsueh WA: Treatment of type 2 diabetic nephropathy by blockade of the renin-angiotensin system: a comparison of angiotensin-converting-enzyme inhibitors and angiotensin receptor antagonists. Curr Opin Pharmacol 2002; 2: 182188.

99. Umeda M, Kanda T, Murakami M: Effects of angiotensin II receptor antagonists on insulin resistance syndrome and leptin in sucrose-fed spontaneously hypertensive rats. Hypertens Res 2003; 26: 485-492.

100.Packer M, Coats AJ, Fowler MB, et al: Effect of carvedilol on survival in severe chronic heart failure. $N$ Engl $J$ Med 2001; 344: 1651-1658.

101.Bristow MR, Gilbert EM, Abraham WT, Adams KF, Fowler MB, Hersberger R: Effects of carvedilol on left ventricular dysfunction and mortality in diabetic versus non-diabetic patients with ischemic or non-ischemic dilated cardiomyopathy. Circulation 1996; 94: I664A.

102.Blumenfeld JD, Sealey JE, Mann SJ, et al: Beta-adrenergic receptor blockade as a therapeutic approach for suppressing the renin-angiotensin-aldosterone system in normotensive and hypertensive subjects. Am J Hypertens 1999; 12: 451459. 